\title{
Exploration of the built environment of age-friendly communities: A Photovoice Study
}

\author{
Qinglai ZHANG, Age-friendly Community Research Centre, Tongji University, China \\ Yuanyi SHEN Age-friendly Community Research Centre, Tongji University, China \\ Yifan YU*, Faculty of Urban Planning, Tongji University, China
}

\section{Abstract}

With the rapid development of rapid urbanization and ageing population, it is very important to actively promote the construction of a safe, comfortable, convenient and agefriendly environment for the elderly. However, older adults are associated with declining health through illnesses and functional decline with age. Neighborhood environment has a significant impact on the health and wellbeing of older adults. Therefore, identifying and creating supportive environments that foster connections between older adults and the environment they live in for aging well.

Photovoice as a research methodology is used in this article, which can offer participants an opportunity to reflect on personal and community strengths, create critical dialogue, share knowledge about personal and community issues, and develop and host a forum for the presentation of their lived experiences and priorities through images, language, and context. This pilot study uses the method of Photovoice to explore aspects of the neighborhood built environment considered by older adults as important in facilitating ageing in place.

Through the perspective of the elderly, each participant was asked to take photos that illustrated age-friendly features they considered essential for supporting their lives in the community. A total of 32 older adults take part in this research who live in the high-density built environment community in Shanghai, China and 196 photos were collected. Subsequently, they write participated in a follow-up individual interview and discussed the positive or negative built environment that affects their daily activities.

All photographs, photo journals and additional write-ups were then collected, organized and coded by researchers. The content of the interviews was analyzed by natural language processing and semantic network analysis. And then the processed text was completed by topic coding, creating categories, abstracting.

The study found that outdoor space and buildings, transportation, and housing are the main built environment characteristics that affect the elderly-friendly community. Firstly, green space, park, sidewalks and square are the topics most concerned by the elderly. The cleanliness and safety of its outdoor space is seen as a barrier to physical activity and daily walking. Secondly, the quality of housing affects the quality of life of the elderly, and the lack of sunlight in the rooms all year round has an impact on the health of the elderly. Thirdly, walkable environment and rich street facilities can support older people's physical activity. In addition, a few themes are more oriented to social context, for example public participation, social inclusion, peer support. This research also demonstrates that photovoice show great advantage in the dissemination of vulnerable person relevant voice, and encouraged critical dialogue between participants, and city stakeholders.

\section{Keywords}

Photovoice, age-friendly communities, built environment, Older people 


\section{Introduction}

Demographic ageing is a global trend which has a profound Impact on human development. There are an estimated 728 million persons aged 65 years or over in the world. In the next 30 years, this number is expected to increase to more than double its present value, reaching 1.5 billion older persons in 2050 (United Nations,2020) . In 2018, older people aged 60 and above reached 18\% of the Chinese population((Dang \& Li, 2019). According to the WHO, providing age-friendly environment will help people to age actively and thereby enhance their quality of life(World Health Organization,2007). Facing the challenges of increasing aging, It is important to adjust the environment for aging.

The theme of developing age-friendly cities and communities emerged from a series of policy proposed by the World Health Organization (WHO) during the early 2000s. The concept of "age-friendly cities" was proposed by the WHO in 2006 to improve the quality of life of older people by encouraging active aging by optimizing health, participation and safety, In 2007, WHO proposed Global Age-Friendly Cities: A guide, aimed at enabling people to have a positive attitude towards old age through policies, services, environment and facilities support. The guide summarizes eight domains in which cities would encounter challenges and in which actions are needed. These eight domains are (1) outdoor spaces and buildings; (2) transportation; (3) housing; (4) social participation; (5) respect and social inclusion; (6) civic participation and employment; (7) communication and information; and (8) community support and health services. (World Health Organization,2007).In 2015,WHO established a framework and set of indicators to evaluate progress in improving the age-friendliness of urban environments $($ WHO,2015) The core indicators were structured around three key principles: equity (such as measured through comparisons between sub-groups and total population), accessibility of the physical environment, and inclusiveness of the social environment.

A substantial body of evidence indicates that physical environment and social environment are important factors affecting the physical and mental health of the elderly.( SAELENS et al.,2003; BOWLING et al.,2007;CUMMINS et al.,2007; VAN HOOF et al.,2021). Owing to face multiple personal and social changes, older adults often limit daily activities to their immediate or nearby surroundings, thus, the neighborhood environment becomes extensively important(WEDEN et al.,2008;CHAUDHURY et al.,2012;LORD et al.,2021).Therefore, it is important to understand older adults' needs in terms of the neighborhood built environment. Many studies on age-friendly communities stresses the importance of older adults' voices and discuss specific meanings given by them to environment relating to place attachment (KOHON et al.,2014).

Photovoice ,as a community-based participatory research (CBPR), engages study participants to take photographs as a method of documentation and communication of a physical-social phenomenon , which can address community needs, stimulate individual empowerment, and create a critical dialogue to advocate community change(WANG et al.,1998;HERGENRATHER et al.,2009). The process has three main goals: a) to enable people to record and reflect their communities strengths and concerns, b) to promote critical dialog and knowledge about important community issues through large and small group discussion of photographs, and c) to reach policy-makers(Wang et al.,1997).

The purpose of this study was to conduct a participatory research process with community older adults using photovoice method to identify the factors of neighborhood physical environment and social environment that influence age-friendly community.

\section{Method}

\subsection{Research setting and participants}


Thirty-two older adults in Tongji New Village, Yangpu District, Shanghai participated in this study. Tongji New Village is located within the inner ring road of Shanghai, with a total area of about $16 \mathrm{hm}^{2}$ and a total construction area of $194,600 \mathrm{~m}^{2}$, forming a large residential area in the urban central district with a total of 3,819 households consisting of low-rise and multi-storey buildings(FIG.1).

The aging of Tongji New Village is as high as $38 \%$, in other words,, more than $1 / 3$ of the community residents are aged 60 or above. Under the increasingly serious aging background, it is urgent to transform the existing built environment for aging to meet the daily needs of the elderly. Therefore, this study takes the elderly in Tongji New Village as the research object and explores the interactive relationship between the elderly's residential behavior and the community environment, which has typical and practical significance.

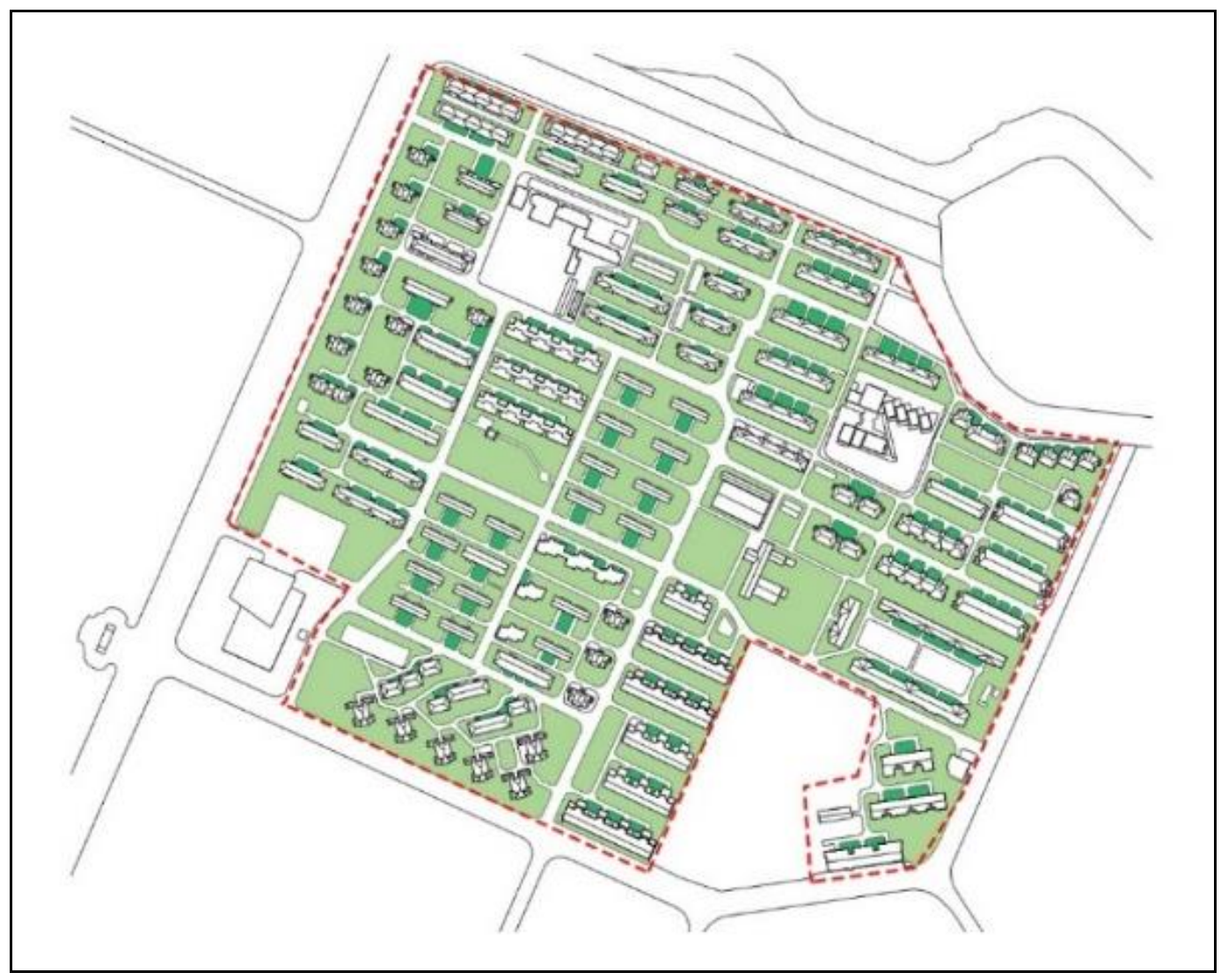

Figure1 Research Base Overview

\subsection{Procedures}

Before starting the project, our research team had formed a good links with the community residents. Through the community committee, we publicized the experiment in each building to recruit the photovoice study participants. Thirty-two older adults (eight men ;twenty-four women ) participated in this study. All participants attended one training/information session before the data collection. The meeting mainly introduced the purpose, method and content of the study to the participants, and asked them to take 10 photos of the environment that they thought was friendly to them and 10 photos of the environment that had negative effects on them. After the meeting, all participants were provided with written information and signed a written consent form.

Participants took photographs over a period of a week. When finishing taking photographs, participants were asked to choose the three most representative photos from each of 10 friendly and 10 unfriendly environments. Then, Semi-structured interviews were conducted. The researchers interviewed each participant for about 45 to 60 minutes. During the interview, participants were asked to answer five 
questions based on the image information: 1). Explain when and where the photo was taken? 2). How did it make you feel? 3). What elements in the picture bring about the above feelings? 4). What activities did you engage in in this environment? 5). From the perspective of improving activity experience, do you have any suggestions to optimize this environment? After the interview, participants were paid 100 yuan.

\section{3 data analysis}

Analysis was conducted of Interview data and photographs in parallel. Interview data were transcribed verbatim to text data. Then, thematic analysis of the text data was completed using three process framework: 1) topic coding 2) creating categories; and 3) abstracting or conceptualizing. Analysis of the photographs was conducted to identify similarities and differences in elderly people's perception of age-friendly environment. Finally, the location information of all images was geocoded by GIS platform, and the spatial distribution characteristics of age-friendly environment were explored by kernel density analysis.

\section{Study on age-friendly community based on text and image information}

\subsection{The theme of age-friendly environment for the elderly}

Natural language processing method was used to analyze the transcripts. After word segmentation, high-frequency words were extracted and words unrelated to the built environment were filtered. by this way, the topic that the elderly were concerned about the age-friendly environment is obtained. In the word frequency analysis results of positive spatial environment (FIG. 2), "green", "movement", "space", "facilities", "neat" and "beautiful" were the high frequency words. In the analysis results of word frequency in negative spatial environment (FIG. 3), "garbage", "bicycle", "parking" and "road" are frequently used. Through the analysis of positive and negative spatial environment experience, it can be found that main concerns to the elderly include outdoor space and architectural elements, such as greening, seats, buildings and fitness, chatting and dancing activities, road and traffic element, such as sidewalk, bicycle and road, housing elements such as houses and buildings. Moreover management, design and other social environment elements are included, too. These high-frequency words can help us understand the relationship between the behavior of the elderly and the interaction of the spatial environment, so as to discover the elements of the elderly age-friendly environment.

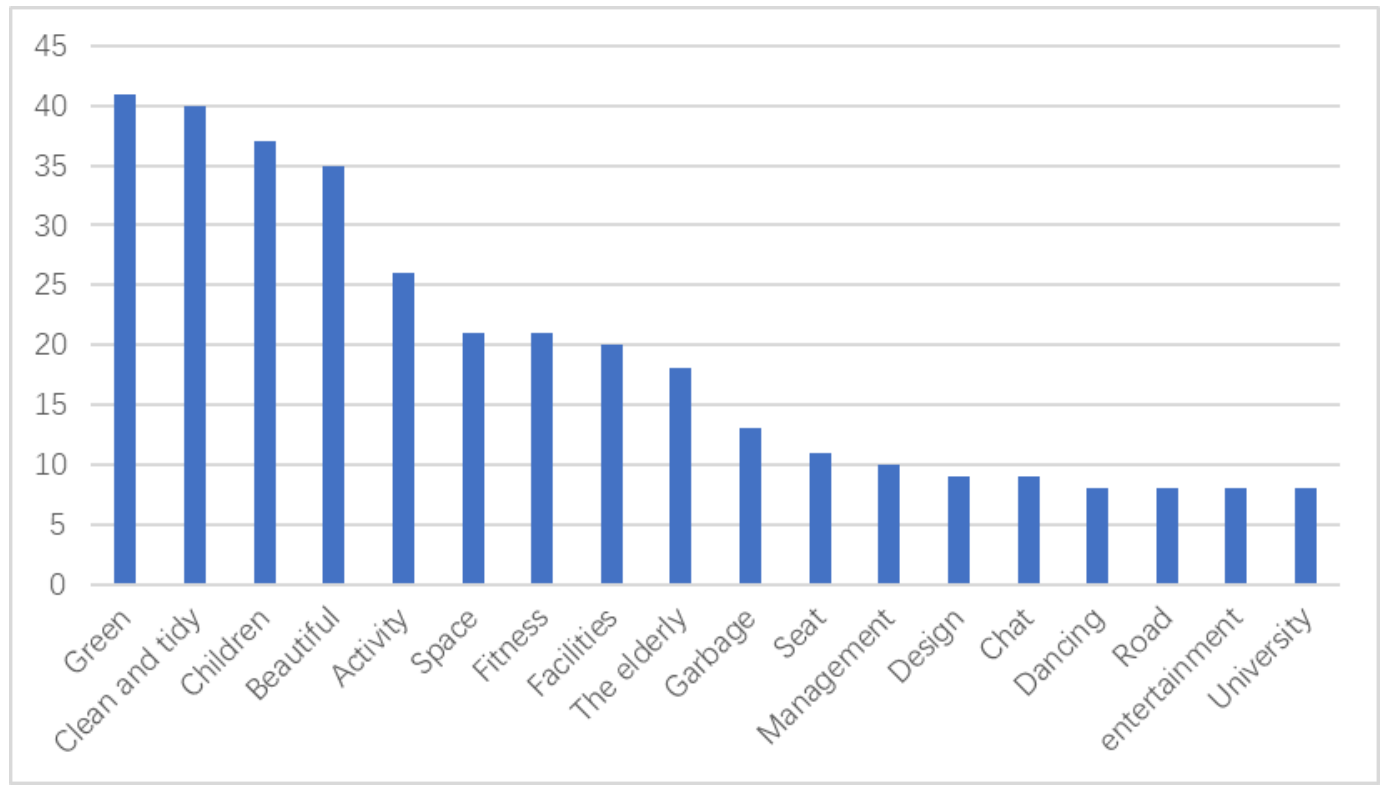

Figure2 Positive environment word frequency statistics 


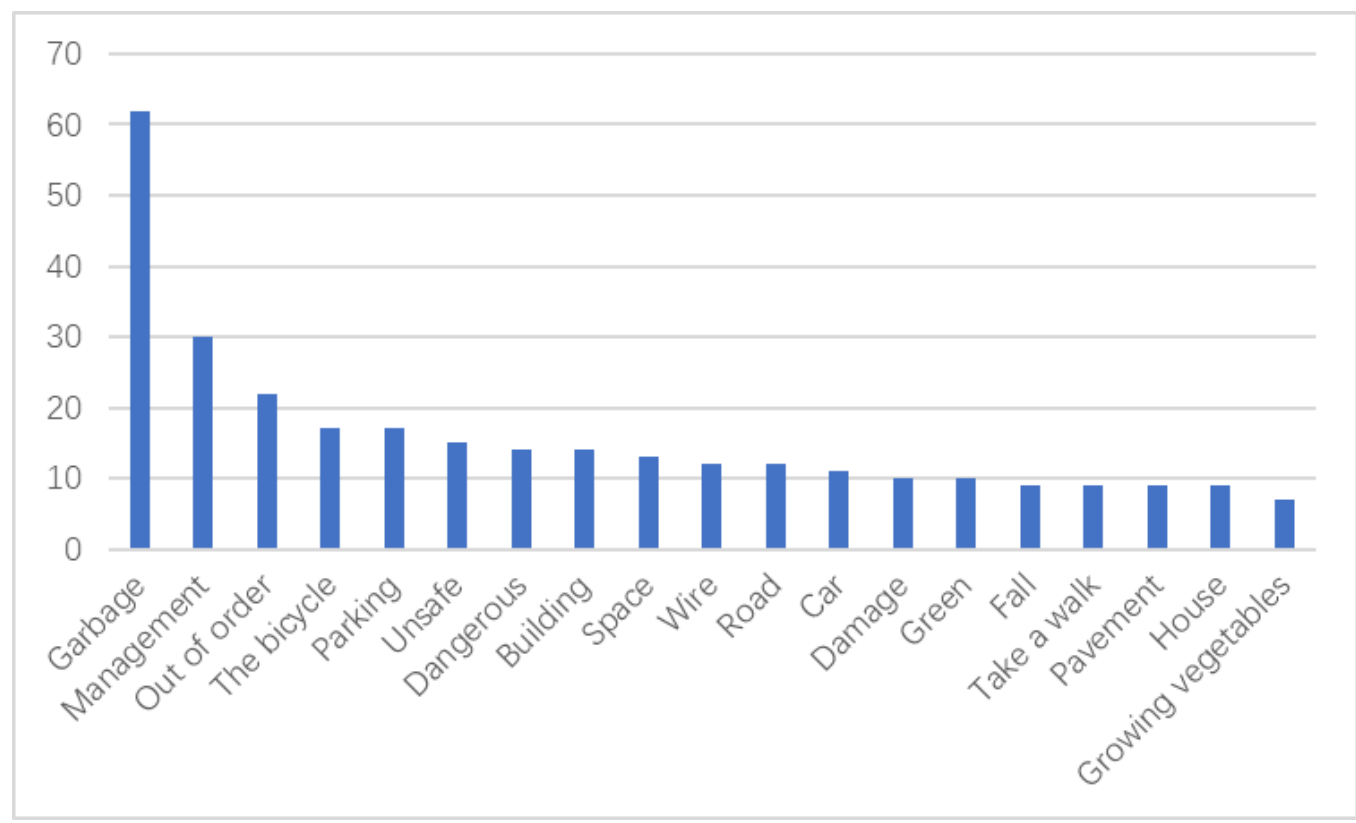

Figure3 Negative environment word frequency statistics chart

Further semantic network analysis was conducted on the transcript, by using ROST ContentMining software to extract high-frequency vocabulary and line feature vocabulary from the text to construct cooccurrence matrix vocabulary, and finally form semantic network analysis graph.It can be found from the results that the high frequency words mentioned above are associated with network structure.According to the semantic network diagram of positive spatial environment (FIG. 4), high-frequency words form associations but cluster structures respectively.It can be seen from the picture that words such as "greening", "place", "environment", "beautiful" and "university" are closely linked with many other elements. It can be found that when the elderly talk about greening, they often mention beautiful, clean, sunny and fitness places. When talking about "space", it involves "dancing", "taijiquan", "exercise" and other activities;When talking about "college", words like "beautiful", "quiet" and "walking" are mentioned.This indicates that the community can provide places and infrastructure for the elderly to participate in and meet their behavioral needs, which is an important element in the construction of a age-friendly environment for the elderly.

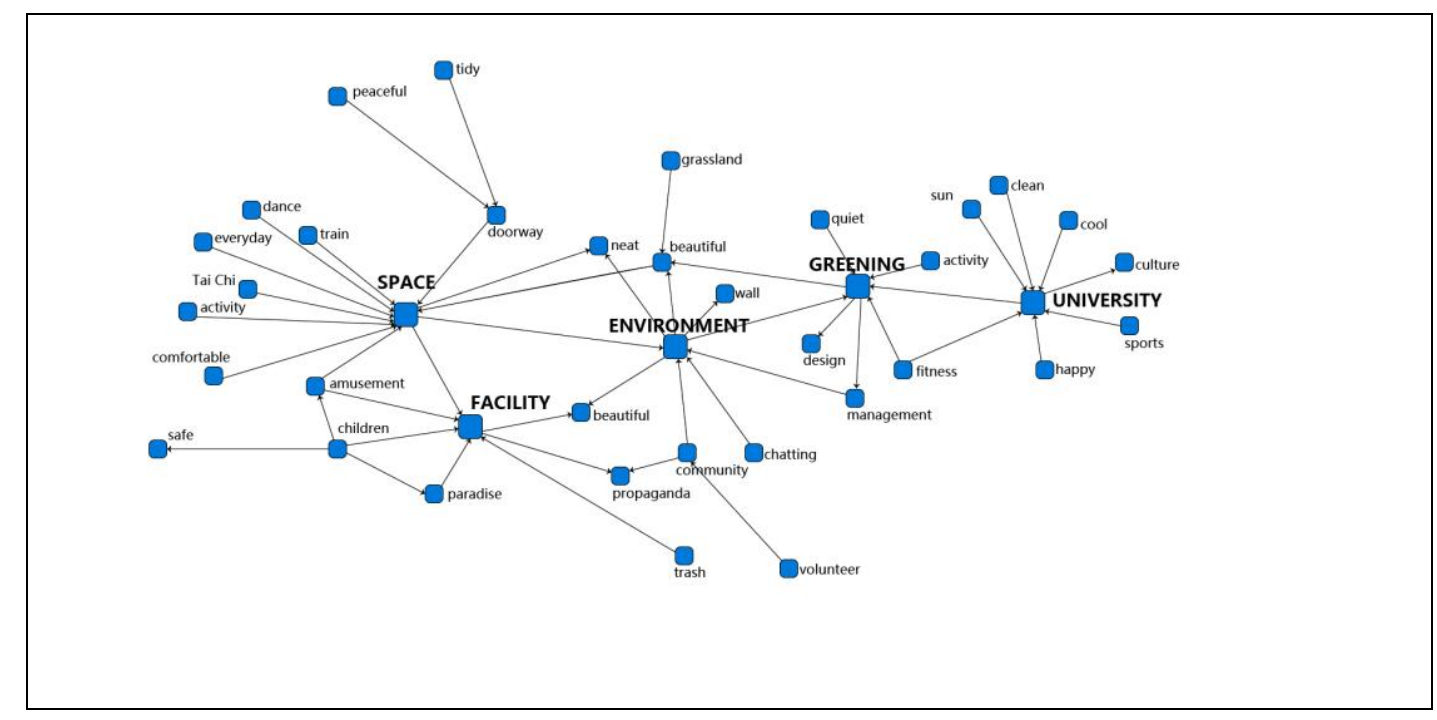

Figure4 Semantic network analysis of positive environment 
From the semantic network diagram of negative environment(FIG.5), high-frequency words such as "house", "road", "environment", "garbage" and other elements form the characteristics of network structure.For example, when the elderly talk about "house", they will refer to sunshine, uncomfortable, shabby; When it comes to "roads", the follow-up talks include "garbage", "parking", "danger", etc.When talking about "environmental" elements, it will involve "garbage", "green space", "management", "danger" and so on.It can be found that the infrastructure and services in the existing built environment are not friendly enough for the elderly, and the elderly are worried about their own safety, which reflects the poor physical space, facilities and housing quality of the existing old communities, and the elderly's low satisfaction with environmental facilities.

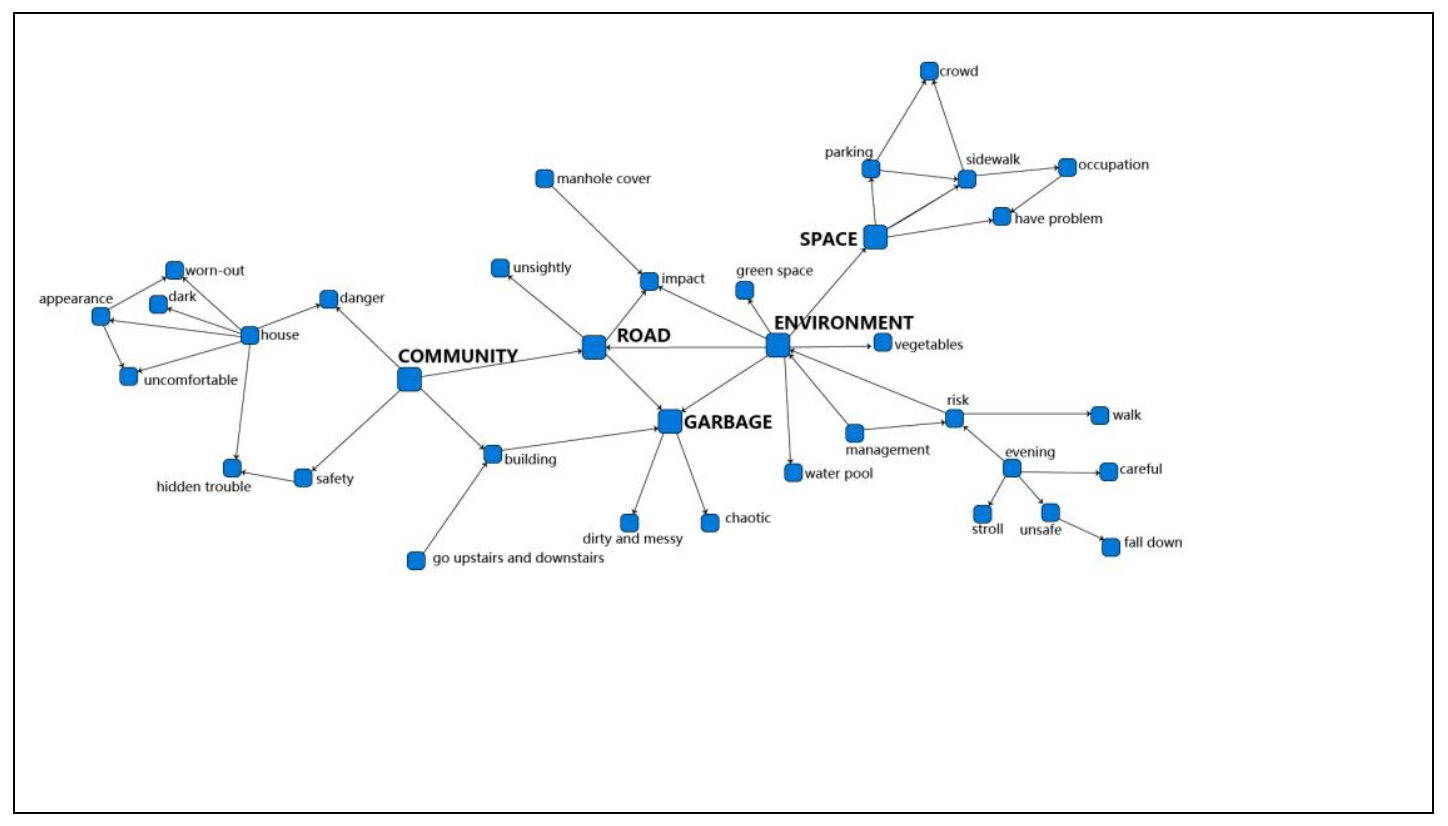

Figure5 Semantic network analysis of negative environment

\subsection{Analysis of factors and characteristics of age-friendly environment for the elderly}

Through word frequency analysis and semantic network analysis of the transcript, we have a preliminary understanding of the elderly's opoinions of the age-friendly environment for them. our team translate and code the description of image information by participants to obtain the corresponding theme of each image, and displays the attention of various themes in the age-friendly environment for the elderly in the form of sankey graph (FIG. 6). The thicker the line, the more attention the elderly pay to this theme.The study found that the elderly age-friendly environment mainly involves two categories of topics, physical space environment and social environment.Physical space environment includes outdoor space and architecture, housing, road traffic three themes;Social environment involves social participation, information exchange and community management. 


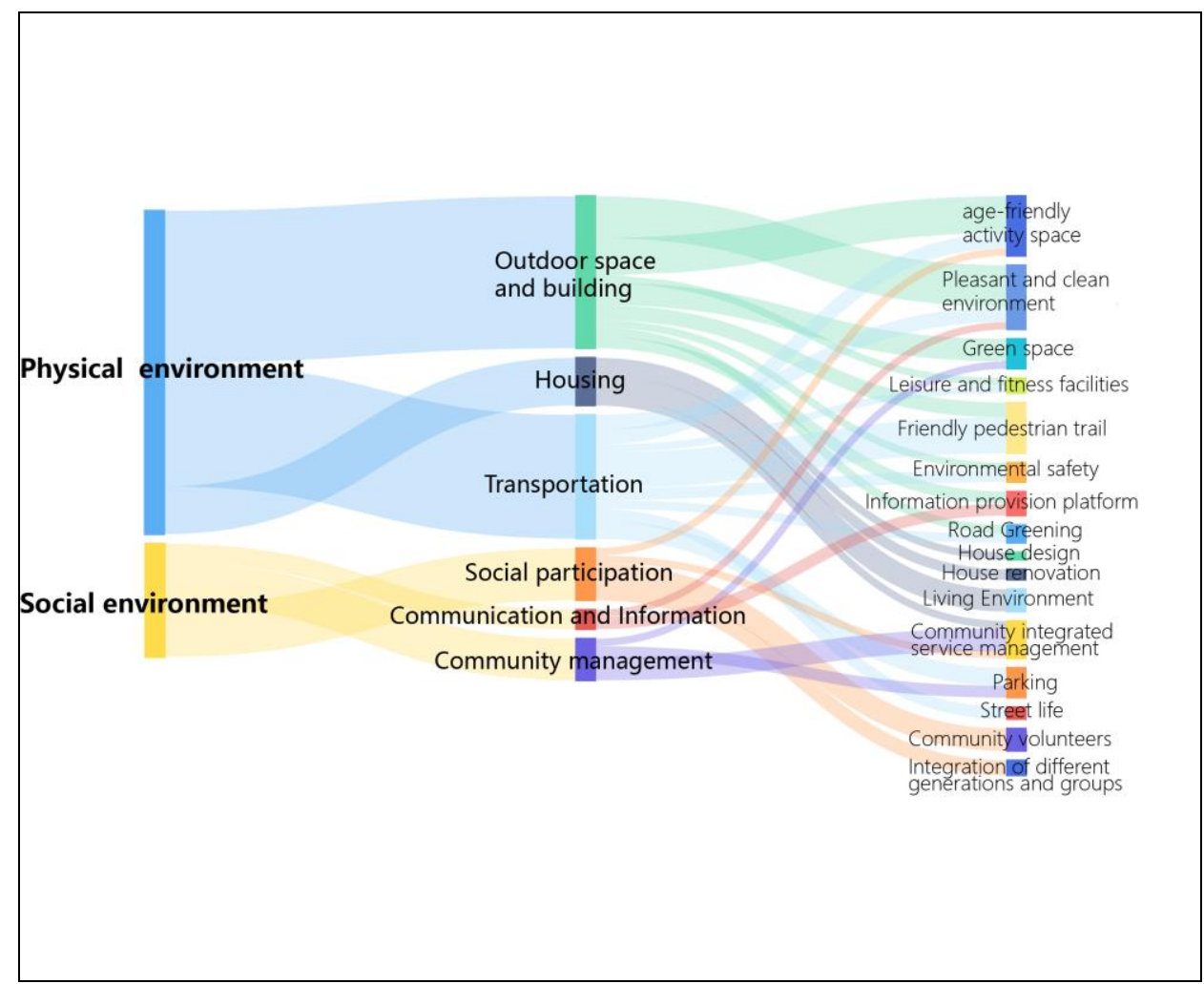

Figure6 Factors of age-friendly environment

\subsubsection{Physical Environment}

\section{(1) Outdoor space and building}

Among the themes of outdoor space and building, topics discussed by the elderly mainly include age-friendly activity space, pleasant and clean environment, green space, rest and fitness facilities, environmental safety and other topics. The elderly pay more attention to the environment that can meet the needs of various activities. A nice outdoor space environment can promote active activities of the elderly and improve their health benefits. It can be seen from the video taken by the elderly that they prefer quiet and dry natural environment, which will bring good mood to the elderly. At the same time, the elderly also pay more attention to the facilities in the environment, such as chairs and fitness facilities, which can increase the possibility of neighborhood communication for the elderly.

From the negative environment images taken by the elderly, it can be seen that the existing built environment is not friendly enough. For example, the elderly are not satisfied with the green space in the community, for it takes a large portion of the open area, but it provides small space for the elderly to do activities.In addition, due to the poor management of the community, the outdoor environment becomes bad. For example, the water system next to the green space becomes smelly, which brings serious baleful effects to the outdoor activities for the elderly (Table 1).

Table 1 Outdoor space and building

\begin{tabular}{c|c}
$\begin{array}{c}\text { positive environment } \\
\text { photography }\end{array}$ & interview \\
\hline
\end{tabular}




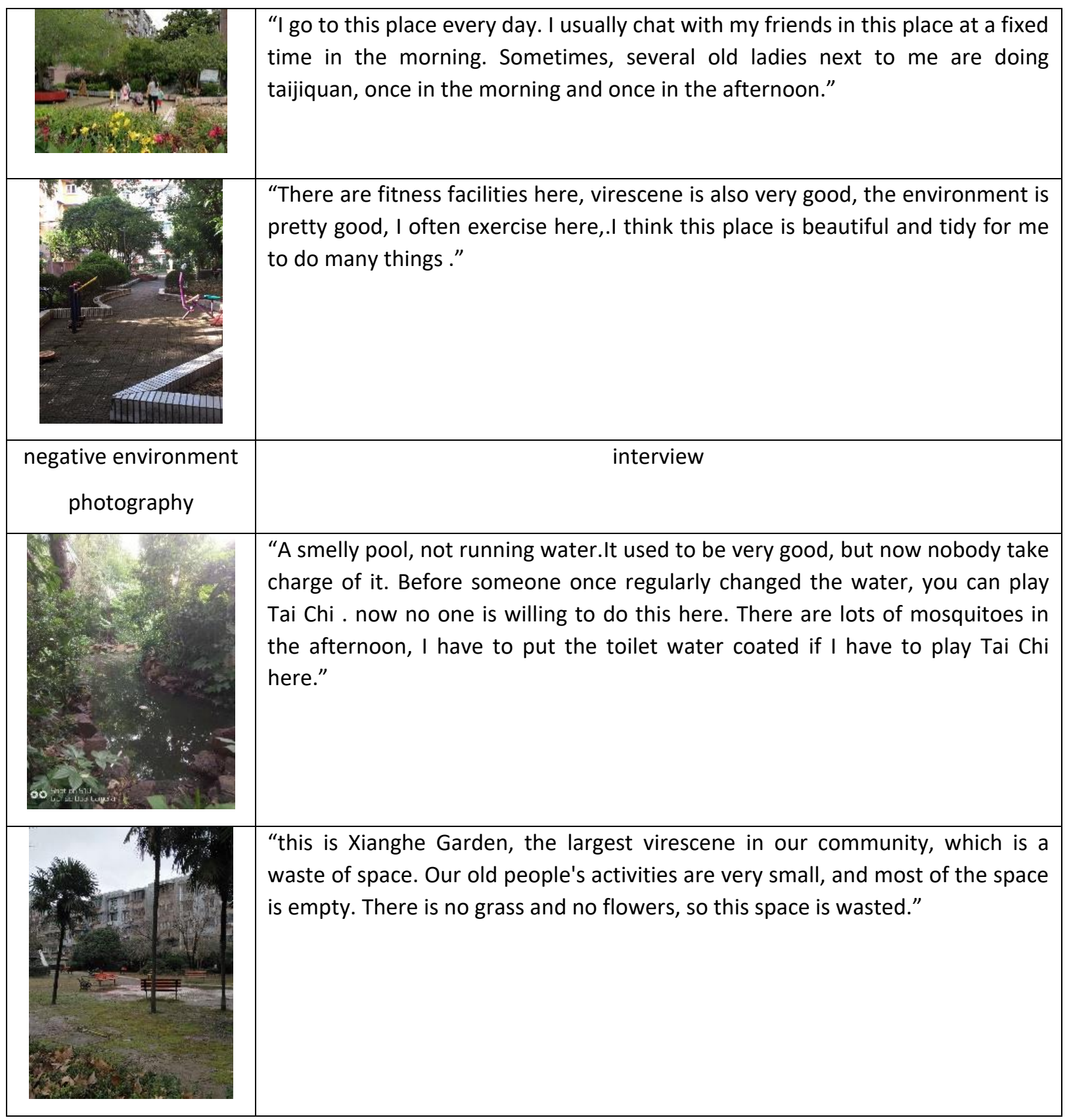

\section{(2) Housing}

The elderly pay attention to the living environment, housing design, housing renovation and so on.The quality of living conditions is an important factor affecting the health of the elderly.Tongji New Village was built in the 1970s. It is a typical public housing community with poor housing quality. With the development of urban renewal, the interior of the community began to be gradually updated and transformed.From the images taken by the elderly, it can be seen that the elderly are more satisfied with the reconstruction of the house.For example, some decorative products and murals outside the housing will be added to the environmental renovation in the housing corridor, which will make the elderly feel comfortable and have a strong sense of belonging.

In the negative environment images, it can be found that the security of living environment is the main concern of the elderly.For example, the elderly put forward a lot of problems about the dilapidated houses in the community and the internal environment of housing such as the height difference. The elderly are prone to fall down due to inconvenient movement, and the existing barrier-free facilities are not friendly enough, which greatly affects the mobility of the elderly.In addition, the light and sound 
environment of the housing is also an important factor affecting the quality of life of the elderly. For example, the elderly mentioned in the interview that the housing in the community lacks sunshine, and some of them also mentioned that the rest at home is easily affected by the activities of outsiders (Table 2).

Table 2 Housing

\begin{tabular}{|c|c|}
\hline $\begin{array}{c}\text { positive environment } \\
\text { photography }\end{array}$ & interview \\
\hline & $\begin{array}{l}\text { "This is the wall decoration of our building, like sculpture, I feel very } \\
\text { comfortable when I come out. Our corridor is so beautiful, and we can also } \\
\text { put photos.I want the whole building to be decorated like this except for the } \\
\text { second floor." }\end{array}$ \\
\hline & $\begin{array}{l}\text { I feel fresh, warm, attractive and beautiful, which is fine with me. } \\
\text { The murals on the wall of the community make me feel in a good mood and } \\
\text { have a strong cultural atmosphere. }\end{array}$ \\
\hline $\begin{array}{c}\text { negative environment } \\
\text { photography }\end{array}$ & interview \\
\hline$E$ & $\begin{array}{l}\text { "This house is too messy, so many things should not be placed at the door, } \\
\text { occupying the public space, it feels uncomfortable, which affects the beauty } \\
\text { of our community." }\end{array}$ \\
\hline & $\begin{array}{l}\text { "This is an illegal building, but there are still people living in it. It is very } \\
\text { uncomfortable to see it built like this. It looks like it is falling down, and } \\
\text { there are very big safety risks." }\end{array}$ \\
\hline
\end{tabular}

(3) Transportation

When talk about road and transportation, the elderly mainly focus on friendly sidewalks, parking, road greening and street life. The mobility of the elderly is closely related to sidewalk design.In the images taken by the elderly, it can be found that the smooth road surface and the greening on both sides of the road are the objects that the elderly pay more attention to, and these elements will affect the activities of the elderly on the road.Friendly sidewalks can promote more active activities in the elderly, which plays an important role in promoting the health of the elderly.In addition, the road space with street life is often an important place to attract the elderly to stop and take part in activities, which plays an important role in the elderly's neighborhood communication.

In the negative environmental photos, parking problems and road safety were the main concerns of the elderly.It can be seen from the image that the static traffic in the community is poorly organized, and 
the motor vehicles occupy the space for activity and rest. The elderly cannot use the space on the sidewalk, which reduces their willingness to travel.In addition, with the development of shared bikes, a large number of non-motor vehicles occupy the sidewalks, making it difficult to form continuous sidewalks.In terms of road safety, many roads in the community have become uneven, which has a great impact on the travel safety of the elderly (Table 3 ).

Table 3 Transportation

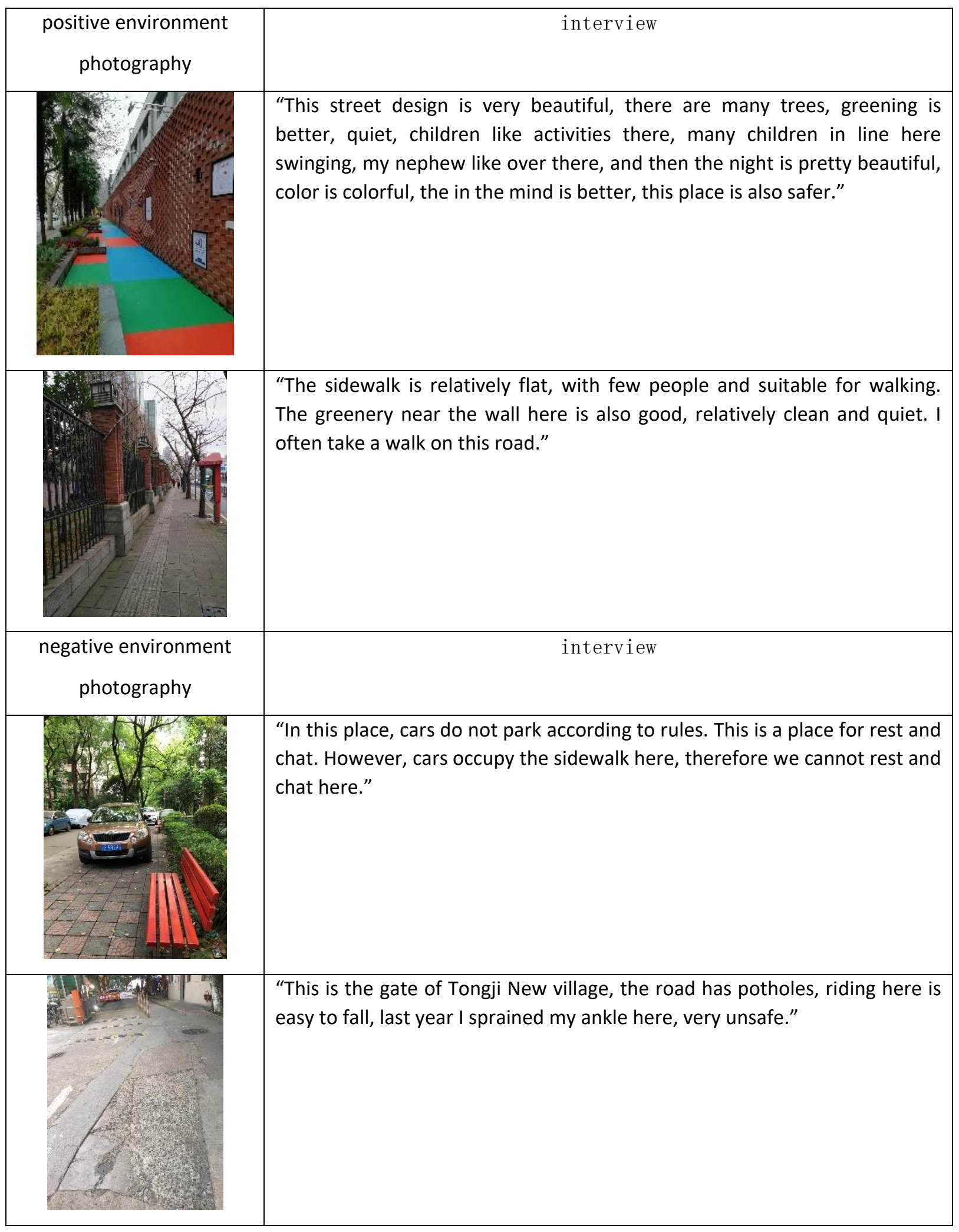




\subsubsection{Social environment}

In the daily life of the elderly, social environment has an important impact on their social integration and mental health. In the social environment, the elderly mainly focus on social participation, communication and Information, community management and other topics.

\section{(1) social participation}

After retirement, the elderly are very active in the community activities, eager to integrate into the society. It can be found in the video information that the elderly want to be volunteers in the community and continue to contribute to the society. When doing social work, the elderly believe that they are respected by the society, which further increases their sense of belonging to the neighborhood. In addition, in the process of participating in community affairs, the elderly can communicate with different generations and groups, so that people of different age groups can enhance their understanding of the elderly and improve their quality of life (Table 4).

Table 4 social participation

\begin{tabular}{|c|l|}
\hline $\begin{array}{c}\text { positive environment } \\
\text { photography }\end{array}$ & $\begin{array}{l}\text { interview } \\
\text { "The sanitation workers have made great contributions to our beautification of } \\
\text { the city. They insist on starting their work early in the morning no matter it is } \\
\text { rainy or snowy in winter. I admire them very much." }\end{array}$ \\
\hline & $\begin{array}{l}\text { "Every time We do volunteer activities, we find our community is really } \\
\text { beautiful, green, background, rockery, chat, old people come to bask in the sun, } \\
\text { the environment is good, we bask in the sun and so on." }\end{array}$ \\
\hline
\end{tabular}

\section{(2) Communication and Information}

Access to timely and effective information through contact with people and events and meeting the needs of the elderly is particularly important for an age-friendly environment.In the images taken, the elderly actively obtain all kinds of information from various ways.For example, the elderly in the process of walking, like to go to the community bulletin board, propaganda board to read information related to the community.

All these indicate that the elderly are actively participating in society, and through information exchange with the outside world, they can reduce their sense of loneliness and gap after retirement (Table 5).

Table 5 Communication and Information 


\begin{tabular}{|l|l|}
\hline $\begin{array}{c}\text { positive environment } \\
\text { inotography }\end{array}$ & $\begin{array}{l}\text { "It is beautiful and practical, the use of space is more obvious, and } \\
\text { the design is beautiful, people often take a look at the newspaper } \\
\text { column, when waiting for bus." }\end{array}$ \\
\hline
\end{tabular}

\section{(3) Community Management}

Good community management can create a comfortable and safe environment for the elderly, which has an important impact on their social interaction and health. In the image information, it can be found that the elderly are not satisfied with the community management. Due to improper management of the community, the environment of the community is not friendly enough, such as the garbage in the community can not be immediately disposed of, and the activities of the community are not properly used. All these will affect the experience of the elderly in outdoor activities (Table 6).

Table 6 Community Management

\begin{tabular}{|c|c|}
\hline $\begin{array}{l}\text { negative environment } \\
\text { photography }\end{array}$ & interview \\
\hline & $\begin{array}{l}\text { "The garbage here has been placed for a long time, but no one has handled it. I } \\
\text { think the main reason is the poor property management, and the garbage is } \\
\text { too big for the volunteers to carry, so it has been piled up here, which affects } \\
\text { the beauty of the community and the traffic." }\end{array}$ \\
\hline & $\begin{array}{l}\text { "This is Xianghe Garden, where we often go for activities. Now, when the car } \\
\text { enters, the lawn is damaged and the ground is getting more and more broken. } \\
\text { If the property management of the community is not strengthened, the grass } \\
\text { in this place will be completely destroyed by the car." }\end{array}$ \\
\hline
\end{tabular}




\subsection{Age-friendly environment system for the elderly}

Geocoding was carried out according to 192 photos taken by the elderly, and the location of each picture was calibrated to the GIS platform. The spatial distribution of positive built environment and negative built environment were obtained through kernel density analysis. The results show that the elderly's perception of the environment is centered on the community, and the environment around the community is the space scope of the elderly's daily activities.

The positive space environment is wider than the negative space environment. In the positive environment, there are three hotspots with concentrated spatial distribution (FIG.7). The first one is the sidewalk outside the School of Design and Creativity of Tongji University, with facilities for pedestrians to rest and entertainment facilities for children. The second community is a square at the southwest gate, which provides enough physical activity space for the elderly as well as chairs and pavilions for rest; The third one is the largest green space in the community, harmony Garden, a space for the elderly to have a social interaction and rest.

In the negative environment, there are three hotspots with concentrated spatial distribution (FIG.8). The first one is the second gate in the southwest of the community, where there is no space for the elderly to stay and the environment is not safe. Bicycles occupy a large amount of space at the gate, affecting pedestrian safety. The second is the west gate of the community, through which the elderly often go to the nearby park. However, garbage and abandoned bicycles are piled up in the corner near the gate, which affects the community environment and aesthetics. The third one is a gate space in the southwest of the community, where the elderly come and go most frequently, but they think the environment is not safe enough. Therefore, it can be found that the community environment for aging is not friendly, and the elderly's needs for physical space environment, social environment and other aspects are obviously different from those of other groups. Therefore, the age-friendly environment for the elderly needs to pay more attention to meet the needs of the elderly, and create a age-friendly environment for the elderly in all aspects.

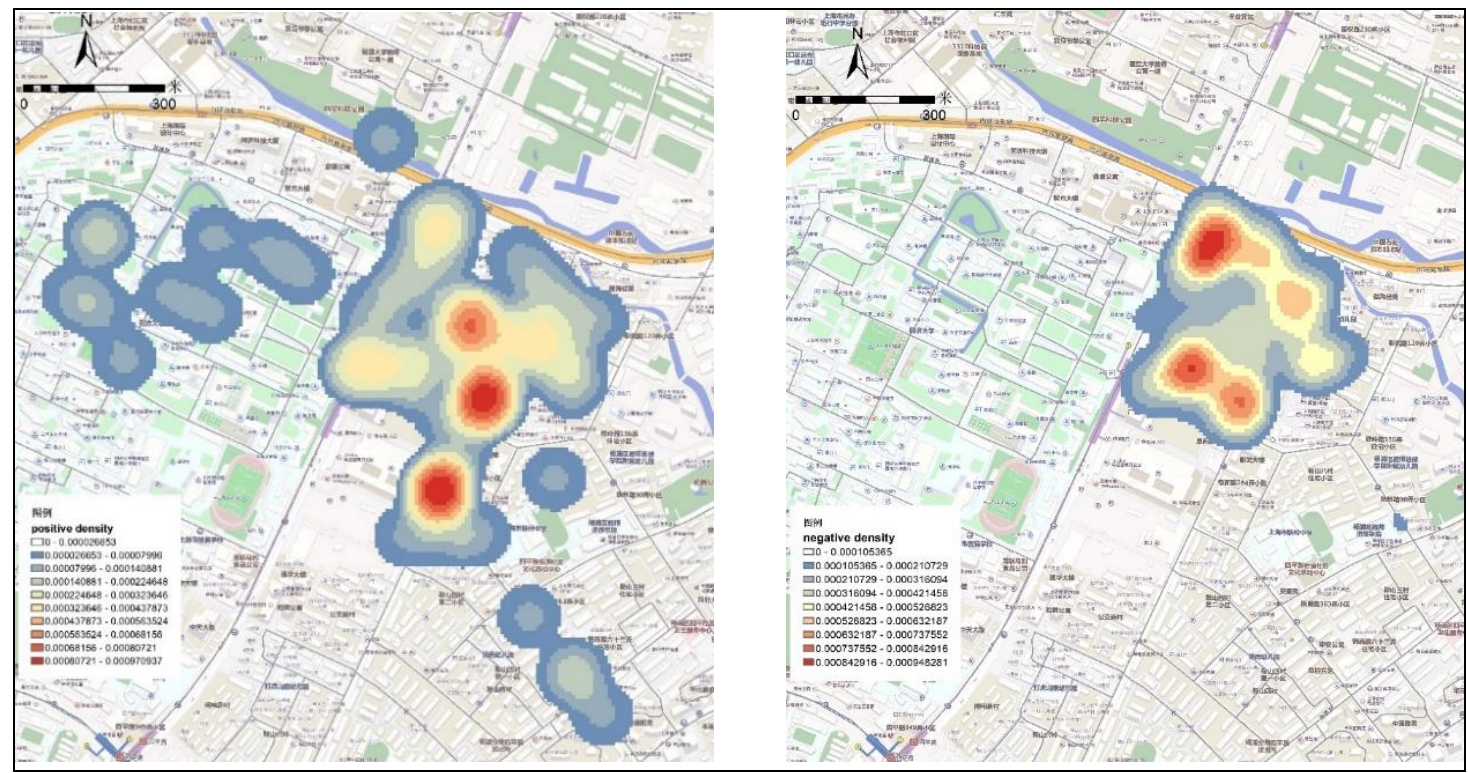

Figure7Spatial distribution of positive environments Figure8 Spatial distribution of nagative environments

\section{Conclusion}

In summary, it is urgent to understand what constitutes age-friendly communities for older adults due to the challenge of an ageing population. This article uses photovoice method to allow the elderly to 
capture the advantages and disadvantages factors that affect their daily life, then, through a semistructured discussion process, it provides an opportunity for the elderly to reflect on the community environment (physical and social) Elements in promoting healthy aging.

The results of the study revealed that the design of age-friendly community should consider not only the physical environment, but also social environment. In physical environment, the elderly mainly pay attention to the three themes outdoor space and buildings, housing, and transportation. in the social environment, the elderly concentrate on social participation, communication and information and community management. The existing built environment is not suitable for aging, and the level of agefriendly community needs to be improved.

In terms of physical environment, outdoor space focuses on creating safe and friendly public spaces and improving the accessibility of public spaces; improving various facilities to meet the activity needs of the elderly, supporting the elderly to perform more healthy behaviors; In transportation, improve the construction of barrier-free system, create a safe walking environment, and reduce the interference of motor vehicles on the travel of the elderly. In social environment, create opportunities for the elderly to participate in and integrate into community activities, strengthen the connection between generations; promote the elderly to participate in voluntary services, and enhance the elderly's sense of belonging in the neighborhood; establish a variety of channels and forms of information exchange platforms to ensure The availability of information for the elderly.

Photovoice has the characteristics of empowering and mobilizing the elderly to actively face the construction of age-friendly environment Through the elderly's participation in community renewal, it can stimulate the elderly to think critically about the built environment of the community and contribute to the sustainable development of the community. This also provides practical suggestions for relevant policy makers and urban planners, and makes up for the limitations of space design through professional experience.

This study mainly collects the subjective evaluation of age-friendly environment through qualitative research method. The particularity and difference of participants in individual characteristics and neighborhood built environment may limit the generality of our conclusions. In future studies, communities with different groups and different built environments can be taken as the research objects to explore age-friendly environment from different perspectives and improve the construction of agefriendly community.

\section{References}

BOWLING, A. \& STAFFORD, M. 2007. How do objective and subjective assessments of neighbourhood influence social and physical functioning in older age? Findings from a British survey of ageing. Social Science \& Medicine, 64, 2533-2549.

CHAUDHURY, H., MAHMOOD, A., MICHAEL, Y. L., CAMPO, M. \& HAY, K. 2012. The influence of neighborhood residential density, physical and social environments on older adults' physical activity: An exploratory study in two metropolitan areas. Journal of Aging Studies, 26, 35-43.

CUMMINS, S., CURTIS, S., DIEZ-ROUX, A. V. \& MACINTYRE, S. 2007. Understanding and representing 'place' in health research: A relational approach. Social Science \& Medicine, 65, 1825-1838.

Dang, J., Li, J. (Eds.). (2019). Development report on the quality of life for the elderly in China (2019)/blue book of ageing]. Social Sciences Academic Press. 
HERGENRATHER, K., RHODES, S., COWAN, C., BARDHOSHI, G. \& PULA, S. 2009. Photovoice as Community-Based Participatory Research: A Qualitative Review. American journal of health behavior, 33, 686-98.

KOHON, J. \& CARDER, P. 2014. Exploring identity and aging: Auto-photography and narratives of low income older adults. Journal of Aging Studies, 30, 47-55.

LORD, S. \& LUXEMBOURG, N. 2007. The Mobility of Elderly Residents Living in Suburban Territories. Journal of Housing For the Elderly, 20, 103-121.

SAELENS, B. E., SALLIS, J. F. \& FRANK, L. D. 2003. Environmental correlates of walking and cycling: Findings from the transportation, urban design, and planning literatures. Annals of Behavioral Medicine, 25, 80-91.

United Nations. 2020. World Population Ageing 2020 Highlights: Living arrangements of older persons. https://www.un.org/development/desa/pd/zh/node/3431

VAN HOOF, J., MARSTON, H. R., KAZAK, J. K. \& BUFFEL, T. 2021. Ten questions concerning age-friendly cities and communities and the built environment. Building and Environment, 199, 107922.

WANG, CC, WK, TAO, ZW \& CAROVANO 1998. Photovoice as a participatory health promotion strategy. Health Promotion International, 13, 75-75.

Wang, C., Burris, M. 1997. Photovoice Concept, Methodology, and Use for Participatory Needs Assessment. Health Education \& Behavior, 24, 369-387.

WEDEN, M. M., CARPIANO, R. M. \& ROBERT, S. A. 2008. Subjective and objective neighborhood characteristics and adult health. Social Science \& Medicine, 66, 1256-1270.

World Health Organization. Global age-friendly cities: a guide[R]. Geneva: World Health Organization, 2007

World Health Organization (2015). Measuring the Age-Friendliness of Cities: A Guide to Using Core Indicators World Health Organization, Geneva, Switzerland 